\title{
Public Sector Transformation via Democratic Governmental Entrepreneurship and Intrapreneurship.
}

\author{
Evangelos Markopoulos ${ }^{1}$, Hannu Vanharanta ${ }^{2}$ \\ ${ }^{1}$ HULT International Business School, Hult House East, 35 Commercial Rd, E1 1LD, \\ London, United Kingdom \\ ${ }^{2}$ University of Vaasa, School of Technology and Innovations, Wolffintie 34, 65200 Vaasa, \\ Finnland \\ evangelos.markopoulos@faculty.hult.edu,hannu@vanharanta.fi
}

\begin{abstract}
Human capital utilization fails under the integration of the knowledge management and leadership disciplines. Public sector organizations traditionally lack effective human capital utilization due to bureaucratic operations and structures that restrict knowledge sharing incentives and initiatives. This, however, can be achieved with knowledge democratization methods that should be related to the obligation public servants have to share knowledge and experiences for the effectiveness and sustainability of their organization. The co-evolutionary organizational culture of the Company Democracy Model can be used to implement such an approach. This paper evolves the Company Democracy Model (CDM) into the Democratic Governmental Intrapreneurship Model (DeGIM) and extends it to the Democratic Governmental Entrepreneurship Model (DeGEM). Furthermore, it proposes an organizational structure through which DeGIM and DeGEM can be applied at the local or national level through a centralized authority that can empower the contribution of the public sector to the national economy.
\end{abstract}

Keywords: Government · Management · Leadership · Public Sector · Transformation · Entrepreneurship · Intrapreneurship $\cdot$ Innovation $\cdot$ Knowledge $\cdot$ Democracy $\cdot$ Applied Philosophy

\section{$1 \quad$ Introduction}

The global workforce is categorized primarily into the employees of the public sector, the private sector and the self-employed individuals. The development and prosperity of a nation is based on the efficiency and productivity of both the public and private sector, through their contribution to the GDP.

The private sector and the self-employed workforce operate in a highly competitive environment, are self-sustained, and do not burden the national budget. On the contrary they contribute progressively to the society and the development of the whole nation, qualitatively and quantitatively, with their innovations, automations, profitability, insurances and tax payments. On the other hand, the contribution of the public sector, remains questionable without direct productivity metrics that can be transformed into tangible results for the economy and the society. 
The average of the global workforce employed in the public sector reaches the an impressive $30 \%$, making the government to be, by far, the largest employer with more than 1.2 billion employees globally [1]. Therefore, the efficiency and productivity of the public sector employees can be a critical factor in the development of the government, the nation's financial stability, and the national fiscal management. Citi indicates that nearly $50 \%$ of the Chinese workforce is somehow in the government sector, with the Japan to be at 3\%, the US at $17 \%$, Greece at $28 \%$ and Germany at $31 \%$ [2].

There are many factors that affect the size of the public sector in each country. Such factors are based on their cultures, progressiveness, political system, temperament, and others. There are countries with a small public sector that obtain similar or even higher development rates from countries with large public sector and vice versa.

The challenge is not to justify the size of the public sector but first to acknowledge the fact that the effectiveness of the public sector contributes significantly to the economy and the stability of a nation. Furthermore, it is important to emphasize the ways the public sector can become more competitive by operating within a similar framework to the private sector.

\section{The Public sector - Economy / Society, Relationship}

In most countries employees entering the public sector obtain permanent job protection and/or professional asylum. Such conditions and privileges eliminate personal and organizational motivation, ambition, innovation and creativity in the workplace and disincentive hard work for career development. This results in low or negative productivity which transforms the public sector into a national cost center with significant negative impact on the national fiscal management and economy and the national development [3].

Increasing the competitiveness and productivity of a nation requires the collective utilization of all productive recourses, including the public sector whose size crucially affects the nation's ability to generate operational added value. Effective public sector authorities can contribute to the quality of administrative services such as on issuing licenses, approvals, assessments, etc. which in turn can speed up investments, employment, extroversion, production and much more. This efficiency also returns to the society not only from the quality of services the citizens receive but also through the job opportunities that are created in a prosperous and progressive nation.

This overall and holistic role of the public sector in a national economy is evolved around the citizen as a double accelerator for the public sector's effectiveness in producing both social shared value [4] and economic wealth (Fig. 1).

\section{Public Sector Human Capital Utilization Preconditions}

The knowledge which exists in the public sector can be categorized on the impact it has in on the society and the economy. Emphasis shall be given to the organizational knowledge that impacts directly the quality of services provided primarily to the society, which is both the citizens and the organizations of the private sector, that belong to the citizens. However, public sector organizations that already operate as private sector 
enterprises selling their products or services to the clients or other private organizations are expected to run as private sector organizations in any case, with established knowledge and human capital utilization methods that effectively and successfully work.

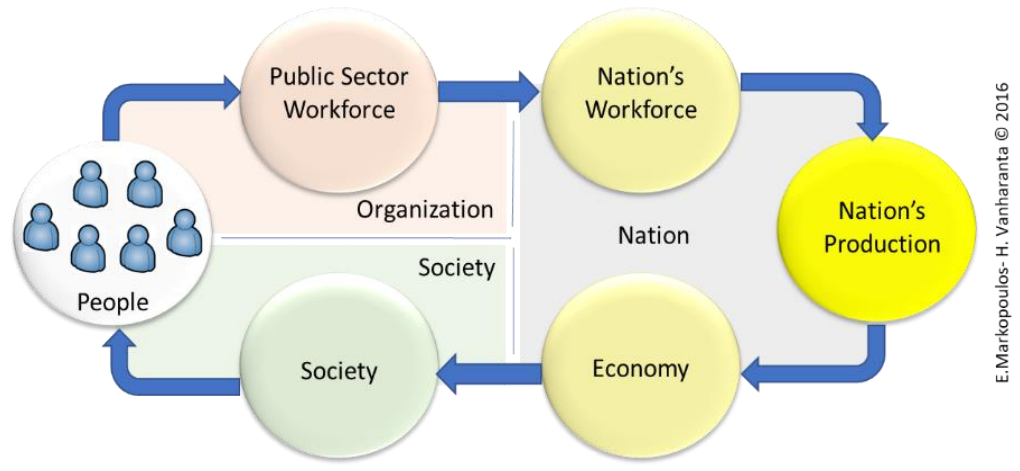

Fig. 1. Cyclical public sector contribution to the national economy and society.

Organizational knowledge is generated over the daily operations and activities of each employee. People can think and act upon their thoughts and learn from their acts. This basic learning process must be supported by a collaborative and co-evolutionary culture which provides the space needed for knowledge elicitation and sharing that will collectively be utilized on each organizational challenge [5]. This culture can easily be established as the collective development and growth ideology, especially in the public sector where the employee solidarity is at a much higher degree than in the private sector. Therefore, the desired human intellectual capital utilization environment that can be effectively applied in public sector organizations shall be based on six staged preconditions which address all the issues from the knowledge creation to the knowledge utilization (Fig. 2).

The first precondition is related to the development of the organizational culture in which all employees can be guided on obtaining active roles based on their professional, and not political skills, ideas, views, and capabilities. Through this culture freedom of speech and act shall be promoted above all. Free speech however must be supported with the practical reasoning for the benefit of the organization and the society. Likewise, freedom to act must be supported with the ability one has to realize, and implement the speech. Freedom of speech and act are fundamental democratic values, a privilege for those willing and wishing to progress, but also a punishment for those who directly, indirectly or creatively stay in the shadows, harming and not helping the organization.

The second precondition is related on applying quantitative and qualitative metrics to the ideas, thoughts, innovations, and initiatives proposed by each employee within a given timeframe. These metrics can identify the overall employee knowledge acquisition indexes to determine promotions, staffing needs, educational needs, or even penalties for those who think and/or act destructively. This approach gives each employee career development control and the opportunity to reach top management positions based on their work and contribution, and not only on academic attainments or political and social networks. 
The third precondition is related to the promotion of a co-evolutionary framework where the right teams, composed from the right people, for the right project, and for the right time, can work together. Employees can be temporarily or partially extracted from their roles and responsibilities and assigned to manage, lead, or participate in the implementation of projects they created, initiated or considered valuable to be part of. This approach offers experiences, work satisfaction and financial compensation through a continuous and rewarding rotation of employees from project to project as project leaders or project members.

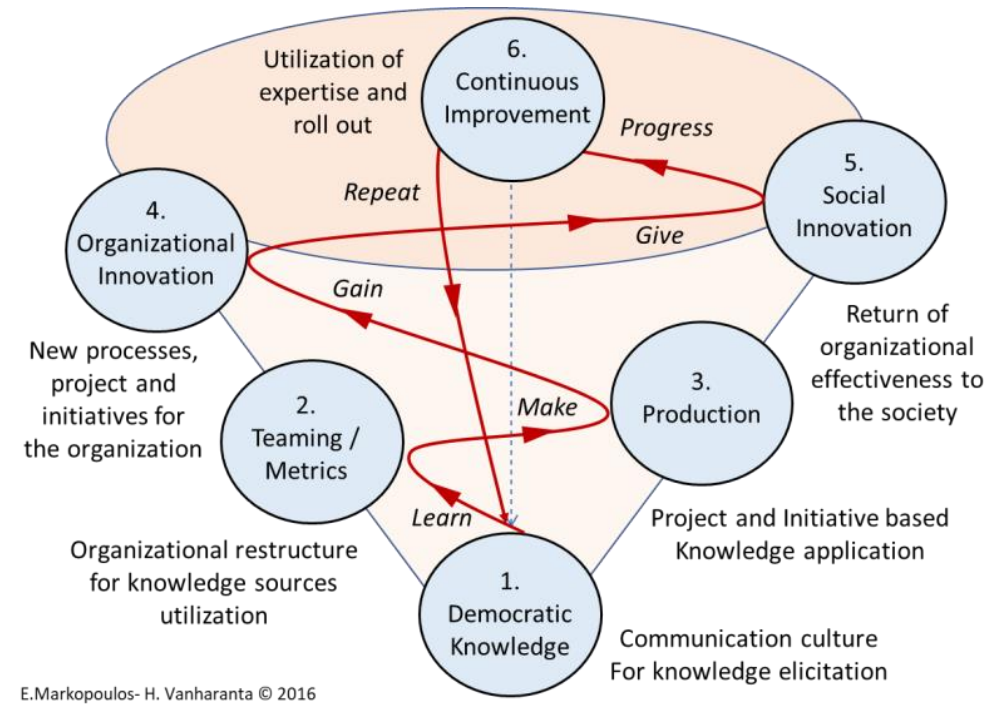

Fig. 2. Public sector knowledge utilization preconditions.

The fourth precondition is based on sharing the idea that the quality of the work produced in an organization is completely related to the lifespan of the organization. This concept can assure qualitative services to be delivered to the nation, the people and the society. Organizations with poor results have no reason to exist and must be shut down or restructured with new employees, releasing the existing ones to the open market of the private sector. It is certain that capable employees will not face challenges re-entering the workforce in the public or private sector.

The fifth precondition is related directly to the society, as public sector organizations are being formed to serve it. Ideas and innovations, through acts and projects, must always have a social impact to the citizens who actually pay and fund the existence of the public sector organizations in the first place. Public sector employees also called 'public servants', since their first and foremost duty is to serve the public. Such shared value effectiveness can be the reduction of bureaucracy, speeding up various processes, reduction of paperwork, corruption restriction and anything that can improve the lives of the citizens and increase the efficiency of the public sector.

The sixth and final precondition is based on a continuous integration of the knowledge generated in the organization back to the into the public sector operations, products and services. This integration ignites the iteration of the five preconditions 
towards a continuous optimization of the overall process under a democratic and effective knowledge management, business management and strategic leadership.

\section{Knowledge Democratization in the Public Sector}

Effective management and leadership rely significantly on knowledge management and sharing [6]. Knowledge sharing however seems to be a massive challenge in the public sector. The permanent positions provided by the governments to their public servants, reduces the motivation needed for their personal development and growth, negatively impacts the organization and the country but also withholds the application and adaptation of any management/leadership theory, model or framework that could be beneficial. Lack of motives however does not necessarily mean and lack of knowledge which probably exist in many public sector employees. The public sector can be, and should be, lead with an emphasis on the utilization of its human assets for high efficiency and effectiveness. These targets can be achieved through the six knowledge management preconditions whose adaptation can democratize the knowledge that exists in the public sector and provide opportunities to the public servants to control their career path, compensation, benefits and opportunities.

The quantity and quality of the public sector in productivity and service execution is a barometer for the development of a country. It is what attracts investments or ignites de-investments of any kind, not necessarily financial. Human capital investments can be more profitable than financial capital investments as brain-drain can be more disastrous than money-drain. However, to achieve such strategic goals the government and the public sector in general shall embrace the values of a democratic co-evolutionary economy through governmental intrapreneurship and entrepreneurship.

One way to approach such a challenge is through the application of the Company Democracy Model (CDM) [7], [8], a framework based on the wisdom of the ancient Hellenic Delphic maxims of 'Know Thyself', 'Metron Ariston'and 'Miden Agan' [9]. The model is aligned with the Co-Evolute methodology that generates intellectual capital by empowering knowledge-based democratic cultures [10]. This co-evolutionary spiral method uses ontologies to identify and capture the capacity, capability, competence, and maturity of the human resources needed to turn such data, information, and knowledge into rewarding innovations [11]. Through a spiral process the model identifies and defines the degree of democracy needed in organizations for their successful evolution through a constant transformation of their tacit knowledge into explicit knowledge [12].

Adjustments on the CDM operations levels can develop a new framework that can empower a Democratic Governmental Intrapreneurship Model (DeGIM) and further extend it into the Democratic Governmental Entrepreneurship Model (DeGEM). At the first stage, the DeGIM attempts to promote the utilization of the human capital to achieves internal operations optimization of the public sector organization with direct or indirect impact on its target groups or the economy the organization serves. The DeGEM, follows as an attempt to further utilize the DeGIM human capital and to support the development of entrepreneurial initiatives by turning the existing knowledge into public sector spin-off organizations or enterprises that deliver new products and services to the existing target groups or to new markets. 
Both models treat the public organizations and the governmental authorities as industry service enterprises that can generate profitability through effectiveness or innovation and serve the private sector, citizens, investors, and other target groups. DeGIM and DeGEM attempt to set new standards and a paradigm on the way countries can manage their public sector through the utilization of their usually underutilized workforce which turns out to be the larger running cost on the national budget.

\section{Democratic Governmental Intrapreneurship Model -DeGIM}

The structure of the Democratic Governmental Intrapreneurship Model (DeGIM), maintains the six levels of the Company Democracy model adjusted to the public sector knowledge utilization strategy preconditions (Fig. 3).

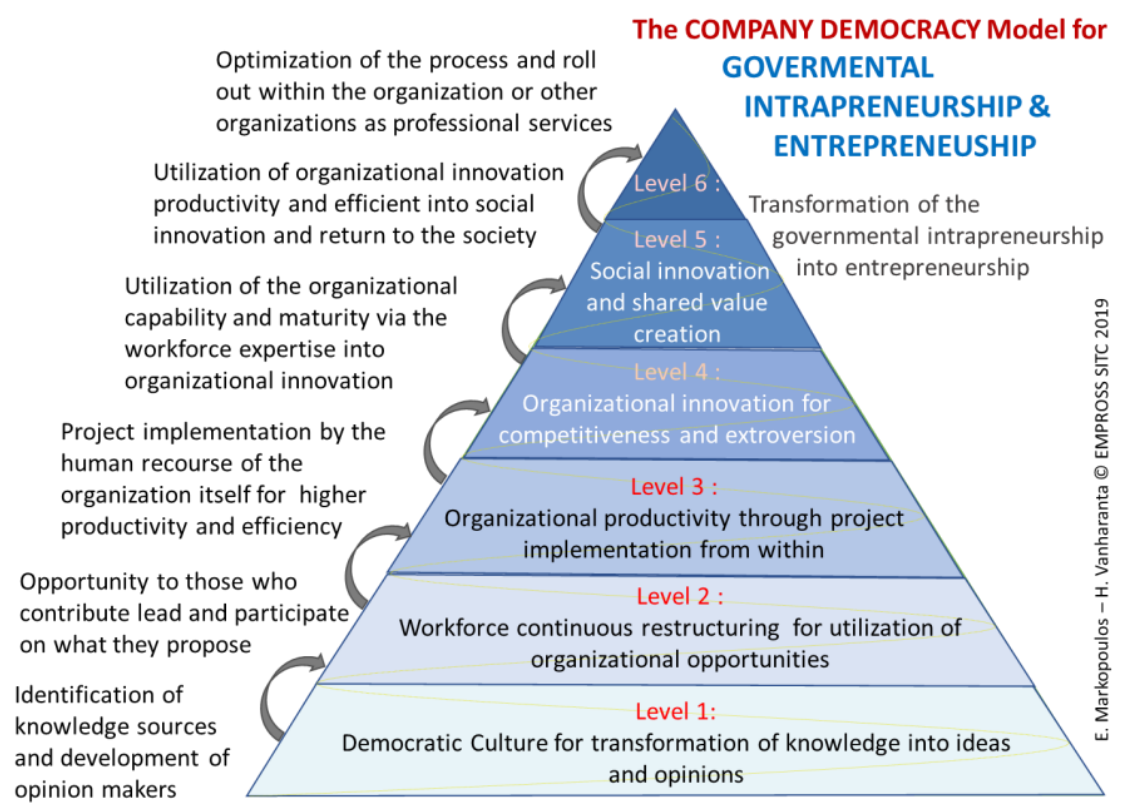

Fig. 3. The Democratic Governmental Intrapreneurship Model.

The first level of the model aims the creation and maintenance of an organizational culture under the principles of democracy and equality. As all employees, public or private, are capable to think, they should be capable then to generate knowledge from their acts. The public sector organizations cannot be an exception to this, as knowledge does exist in them but what seems to be missing is the organizational culture and process to transform this knowledge into valid opinions, actions, ideas, projects and strategies. This first level establishes the co-evolutionary culture as a foundation for organizational knowledge elicitations and utilization.

The second level promotes the co-development and co-operation concept. Since public sector employees have high syndicate bonds, the teaming concept is the best way to promote effective collaborations via co-opetition and not competition. This can be 
achieved by team formations based on the knowledge identified in the first level of the model. The teams composed to utilize this internal knowledge are lead from the ones the knowledge derived. It is common in public organizations ideas and visions generated by the employees themselves to be managed and implemented, with significant cost, by external organizations of the private sector. Level two promotes the concept that the public sector employees are capable to implement their ideas and proposals, receive credit for their contributions, and benefit from their successes.

The third level addresses the actual implementation of the ideas, insights, initiatives, innovations, and projects, derived from the public servants themselves at level one, and staffed with their colleagues at level two. This level allows public servants and organizations to demonstrate their skills, ability, capability, and competence to actually implement effectively and successfully their own projects, and bring significant benefits to the organization, the economy, and society. If public sector organizations can implement most, if not all, of their projects, then the funds allocated for outsourcing project implementation and management can be either fully saved or reduced to a minimum. Such savings impact directly the organization's budget, and the nation's expenditures. Furthermore part of these savings can either be returned to the employees who participated in the implementation of each project as productivity bonus, or used to hire term-based personnel to support project implementation. This approach reduces unemployment and increases the reputation of the organizations and the government to the society.

The fourth level emphasizes on the value returned to the organization in terms of competitiveness, innovation, and quality of services. It is the benefits harvesting period and the recognition on the efforts placed by the right people on the right project for the right time. It is also the level in which the organization can design and execute the best possible communication strategy to promote the effectiveness of the democratic governmental entrepreneurship/intrapreneurship programme. Furthermore, it is the level where the organization can build on the results of level three to optimize the achieved results and turn them into innovative processes, products and/or services.

The fifth level extends to the transformation of the achievements accomplished at level four into shared value innovations to maximize the return to the society by integrating feedback and knowledge from the society itself. Such shared value can be the design and implementation of services, and products as well, with social impact or for social purposes where the benefit for the organization and the society can be mutual and multiple. Social innovation can derive from shared value innovations which can derives from product/service innovation.

Lastly the sixth level of the model is related to the continuous improvement and the extroversion of the results achieved by the public sector organization through the Democratic Governmental Intrapreneurship Model. At this level the model turns from a Democratic Governmental Intrapreneurship (DeGIM) to a Democratic Governmental Entrepreneurship Model (DeGEM). This is achieved with the extroversion of the successful intrapreneurial activities and their transformation into organizational spin-offs, start-ups, business units, product lines or services lines. This is also the level where the effectiveness of the organization can also be exported internationally, to foreign governments, as new expertise, know-how, products or services.

The operations framework for the DeGEM have actually the same processes found in level six of the Company Democracy Models for Innovation Competitiveness and 
Extroversion. Once the public sector organization enters the DeGEM spiral, the team, the business unit or the department that runs a project, product or service is transformed into an autonomous organizational unit that shall function now under the private sector standards in management, compensation and operations in order to achieve high returns on investments and operations self-sustainability.

\section{DeGIM Implementation Challenges}

The implementation of the overall framework of democratic governmental intrapreneurship and entrepreneurship is a Y theory model based on strategic management and leadership skills. However, implementing such models in the government require a number of legislative and legal support activities to resolve challenges that might arise on setting up the execution infrastructure.

One of the key challenges the model must overcome is the power an organization needs to move employees into positions related to their knowledge contribution, abilities and expertise. The model rewards those who have the knowledge and want to apply it by offering career opportunities within the organization's hierarchy outside the traditional career progression path. Furthermore, it is also important for the organization to be able to properly reward the employees who share organizational knowledge, document best practices, participate in the governmental entrepreneurship with ideas, make suggestions and work hard to implement them. Flat hierarchy models with legislative restrictions on the promotion processes and compensations schemas, restrict the implementation of the model.

The identification of the department or division in the organization that can first apply the DeGIM is one more challenge. It is wise to apply the model first on the most mature department of the organization which can be used as a success story or example of progressiveness. Ideal departments that can be used as pilots are those that heavily interact with the citizens and the society or produce a product or service. In these cases qualified and quantified success indexes can be applied. In the first case the department can come up with new services that benefit the citizens, while the in the second case the effectives of the model can be related with the revenue increase and/or the profitability of the organization that derived from its clients. Both types of departments can produce different results for different goals, but with the same success factors and impact.

\section{Democratic Governmental Entrepreneurship Authority - DeGEA}

Once the DeGIM and DeGEM models get rolled out to more public organizations a critical challenge can be on their credibility and application consistency between the various organizations.

This can be managed with the creation of the Democratic Governmental Entrepreneurship Authority (DeGEA), an independent authority that can standardize the DeGIM and DeGEM models as structured methodologies on which public sector organizations can be assessed and score on process effectiveness and standards compliance. DeGEA 
can obtain ownership of the models, turn them into national standards, document its execution processes in detail, formalize an assessment process and create a pool of auditors/inspectors to inspect each organization over specified time periods. These audits shall be delivered by qualified inspectors on the effective and proper execution of each model where an official compliance score will be given. According to the organization's performance, level-based certificates can be issued each time an organization fulfills the requirements of a level.

This DeGEA shall not only assign quality management inspectors to assess the organizations, but must also provide consulting, coaching, support and training to the organizations committed on the models. Furthermore DeGEA can be responsible for handling the legislation challenges that could be faced by the public organization on the implementation of the model (Fig. 4).

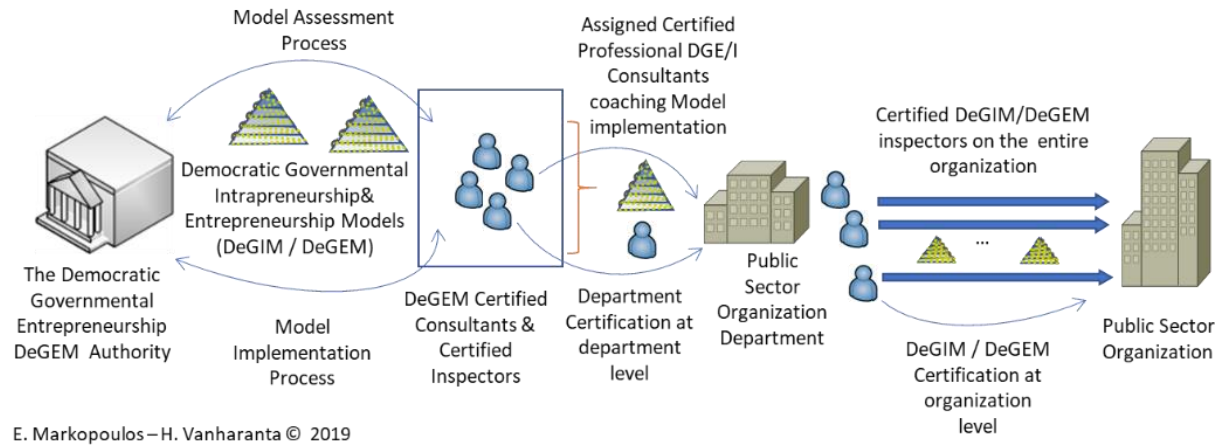

Fig. 4. Proposed operations of DeGEA.

Besides the certificates offered to the organization for successfully completing a DeGIM level, the certification can be extended to the employees as professional skills certificates based on their model participation scorecard. This can verify the degree of their commitment to successfully contribute and implement the model within the organization. These certificates can be associated with salary increases and other professional and career development benefits and privileges.

The design for the implementation of the Governmental Entrepreneurship/Intrapreneurship Model in central government and its support to the public sector organization has low-financial cost strategic initiative. However, it is a high-commitment cost initiative for the political leaders that will be called to promote such transparent public sector management models, which can return them high reputational benefits.

\section{Conclusions}

The DeGEM, the DeGIM and the DeGEA can be considered as strategic transformational initiatives on the management and operations of the public sector. The value of the human intellectual capital that resides on the public sectors can be national wealth and valuable fuel for the growth and the development of a country [13]. It is also a leadership challenge to tackle issues that have not been managed effectively for 
centuries [14]. The job security offered by the public sector organizations and the lack of effective performance evaluation of not only the personnel, but at the organizations themselves is what primarily blocks any improvement transformation regardless how effective and absolutely necessary can be for the private sector. It is therefore a matter of strategic and authentic leadership that can move such initiatives from theory to practice, with pilot projects initially and with national programs after.

The transformation of public sector operations management towards private sector standards, under governmental leadership is neither a wise nor an unnecessary concept. It is an absolute necessity and a demand, to a great extent, of the people, the citizens, who invest on the public sector performance and existence. It is a necessity for all private sector organizations to generate multiple types of shared value and establish a culture that can lead a society and a nation to progression and prosperity.

\section{References}

1. James P., O’Brien R.: Globalization and Economy. Vol. 4: Globalizing Labour. London: Sage Publications. (2016).

2. Business Insider. http://www.businessinsider.com/chart-of-the-day-government-sector-employment-2011-11

3. Economics Help. UK Office of National Statistics https://www.economicshelp.org/blog/7617/economics/economic-growth-during-great-moderation/

4. Markopoulos E., Vanharanta H.: The Company Democracy Model for the Development of Intellectual Human Capitalism for Shared Value. Procedia Manufacturing, vol 3, pp 603--610 (2015)

5. Markopoulos E., Vanharanta H.: Space for Company Democracy. In: Kantola J., Barath T., Nazir S., Andre T. (eds) Advances in Human Factors, Business Management, Training and Education. Advances in Intelligent Systems and Computing, vol. 498. Springer (2017)

6. Asrar-ul-Haq M., Anwar S.: A systematic review of knowledge management and knowledge sharing: Trends, issues, and challenges, Cogent Business \& Management, 3:1 (2016)

7. Markopoulos E., Vanharanta H.: Democratic Culture Paradigm for Organizational Management and Leadership Strategies - The Company Democracy Model. Proceedings of the 5th International Conference on Applied Human Factors and Ergonomics AHFE 2014 (2014).

8. Vanharanta H., Markopoulos E.: Creating a Dynamic Democratic Company Culture for Leadership, Innovation, and Competitiveness. 3rd Hellenic-Russian Forum. Sept.17. (2013).

9. Parke H., Wormell D.: The Delphic Oracle, Basil Blackwell, vol. 1, pp 389 (1956).

10.Kantola, J., Vanharanta, H., Karwowski, W.: The Evolute System: A Co-Evolutionary Human Resource Development Methodology. In the International Encyclopedia of Ergonomics and Human Factors. Karwowski, W., CRC Press. (2006).

11.Paajanen, P., Piirto, A., Kantola, J., Vanharanta, H.: FOLIUM - Ontology for Organizational Knowledge Creation. 10th World multi-conference on systemics, cybernetics, and informatics. (2006).

12.Nonaka I., Takeuchi H., The Knowledge-Creating Company: How Japanese Companies Create the Dynamics of Innovation, New York, Oxford University Press (1995).

13.Bontis N., Fitz-enz J.: Intellectual capital ROI: a causal map of human capital antecedents and consequents, Journal of Intellectual Capital, vol. 3 Issue: 3, pp 223--247 (2002)

14.Kelly, C.: Bureaucracy and Government. In N. Lenski (Ed.), The Cambridge Companion to the Age of Constantine. Cambridge Companions to the Ancient World, pp. 183--204. Cambridge: Cambridge University Press. (2005). 